\title{
Adaptation and fixation in entrepreneurial approaches of a dental laboratory
}

\begin{tabular}{|c|c|}
\hline \multicolumn{2}{|c|}{$\begin{array}{l}\text { Authors: } \\
\text { Cornelia M. Ferreira }{ }^{1} \\
\text { Jan P. Grundling }{ }^{2}\end{array}$} \\
\hline \multicolumn{2}{|c|}{$\begin{array}{l}\text { Affiliations: } \\
{ }^{1} \text { Business School, Tshwane } \\
\text { University of Technology, } \\
\text { South Africa }\end{array}$} \\
\hline \multicolumn{2}{|c|}{$\begin{array}{l}{ }^{2} \text { Department of Management } \\
\text { and Entrepreneurship, } \\
\text { Tshwane University of } \\
\text { Technology, South Africa }\end{array}$} \\
\hline \multicolumn{2}{|c|}{$\begin{array}{l}\text { Correspondence to: } \\
\text { Cornelia Ferreira }\end{array}$} \\
\hline \multicolumn{2}{|c|}{$\begin{array}{l}\text { Email: } \\
\text { ferreiracm@tut.ac.za }\end{array}$} \\
\hline \multicolumn{2}{|c|}{$\begin{array}{l}\text { Postal address: } \\
\text { Tshwane University of } \\
\text { Technology, Private Bag } \\
\text { X680, Pretoria 0001, } \\
\text { South Africa }\end{array}$} \\
\hline \multicolumn{2}{|c|}{$\begin{array}{l}\text { Dates: } \\
\text { Received: } 27 \text { Mar. } 2013 \\
\text { Accepted: } 26 \text { Mar. } 2014 \\
\text { Published: } 19 \text { Aug. } 2014\end{array}$} \\
\hline \multicolumn{2}{|c|}{$\begin{array}{l}\text { How to cite this article: } \\
\text { Ferreira, C.M. \& Grundling, } \\
\text { J.P., 2014, 'Adaptation and } \\
\text { fixation in entrepreneurial } \\
\text { approaches of a dental } \\
\text { laboratory', Acta Commercii } \\
\text { 14(1), Art. \#188, } 7 \text { pages. } \\
\text { http://dx.doi.org/10.4102/ } \\
\text { ac.v14i1.188 }\end{array}$} \\
\hline \multicolumn{2}{|c|}{$\begin{array}{l}\text { Copyright: } \\
\text { (C) 2014. The Authors. } \\
\text { Licensee: AOSIS } \\
\text { OpenJournals. This work } \\
\text { is licensed under the } \\
\text { Creative Commons } \\
\text { Attribution License. }\end{array}$} \\
\hline \multicolumn{2}{|l|}{ Read online: } \\
\hline 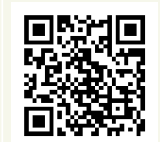 & $\begin{array}{l}\text { Scan this QR } \\
\text { code with your } \\
\text { smart phone or } \\
\text { mobile device } \\
\text { to read online. }\end{array}$ \\
\hline
\end{tabular}

Orientation: This study described the adaptation and fixation processes implemented by a small business entrepreneur in order to cope with changing market circumstances.

Research purpose: The study described how the dental laboratory adapted its entrepreneurial approaches over time in response to critical changes that occurred and how aspects in the managerial approach became fixated and proved to be essential to success.

Motivation for the study: The study provided insight into how the dental laboratory transformed into a stable and prosperous laboratory by the integration of strategic, economic, cultural and social capital through a process of business decision making.

Research design, approach and method: A cohort survey research design, based upon the compilation of longitudinal data over three selected time periods, was employed. The design of the measuring instruments and the interpretation of research results were derived from an adapted entrepreneurial-in-network theoretical framework. A triangulation data compilation approach was followed.

Main findings: The results revealed that cultural capital in the dental laboratory became fixated on three value principles, whilst the other critical capitals prescribed exist in sufficient volumes and improve to adapt to changing circumstances in the dental market.

Practical/managerial implications: Fixated cultural values acted as a 'parent'-actor in order to guide the righteousness of behaviour, whereas adaptation required sufficient critical capitals and the proper integration thereof.

Contribution/value-added: By adopting the entrepreneurship-in-network approach, the researchers incorporated the dynamic and interactive processes of entrepreneurship. Future studies may employ the same design and use multi-varied analyses to show how a business adapt or fixate its approaches in response to crises or changes in the business environment.

\section{Introduction}

Business growth, adaptation and fixation represent complexities that need to be studied within a co-evolutionary process framework in order to give recognition for the fact that relationships between actors and between businesses, as well as the way in which resources are consumed and configured, have a dynamic interplay. These complex processes cannot be studied following a one-stage-at-a-time approach. Researching business adaptation and fixation from a value-creation perspective depends on: (1) matching the necessary resources available to the entrepreneur with perceived market needs; (2) successful exchanges between entrepreneurial offerings and opportunities available in the marketplace; and (3) adapting to changing circumstances in the marketplace (adaptation), whilst at the same time maintaining those approaches and practices that have proved to be essential to success and require minimal change over time (fixation) (Van der Sijde 2007). This research focused on adaptation and fixation in the entrepreneurial process of a dental laboratory. Considering both changes and stability in the utilisation of critical capitals is essential with regard to investigating the appropriateness of business responses to dental environmental changes over time.

The relevance of this study derived, firstly, from the priority placed by the South African government on the development of small-, medium- and micro-sized enterprises (SMME) in South Africa. Ipso facto, this implies a need for available information that can be accessed by other SMMEs to learn from, adopt or apply in their own business endeavours. Secondly, this case is of particular interest because of the rapid business expansion and growth of the dental laboratory over a relatively short time-span of 16 years. It transformed itself from a small, unstable dental laboratory to one of the biggest dental laboratories in the Tshwane Metropolitan area, positioning itself as an interesting case study of a successful business venture. Thirdly, this case is able to 
provide valuable adaptation and fixation information for prospective entrepreneurs in a developing country such as South Africa. Valuable knowledge can be gained from this study that will benefit entrepreneurial development.

\section{The research problem}

The research was based upon two critical questions, namely:

- How did the dental laboratory adapt its entrepreneurshipin-network approach over its lifespan of 16 years?

- Has any aspect of the entrepreneurship-in-network approach in the dental laboratory become fixed or ingrained over its lifespan of 16 years?

Obtaining answers to the above questions could provide an indication of the changes that did or did not occur in the entrepreneurial process, as well as the critical factors that brought about these changes. These answers would then allow the researchers to deduce the specific principles by which the dental laboratory had achieved business success resulting from business adaptation and fixation.

\section{The theoretical framework}

The concept 'entrepreneurship' has resulted in divergent conceptualisations, theories and definitions. The scholarly work on the part of Timmons (1999), Coulter (2001), Zimmerer and Scarborough (2002) and Kuratko and Hodgetts (1992), with regard to defining entrepreneurship, entrepreneurial theories and change, indicates that each attempt followed unique conceptualisations and discourses. For this reason, an appropriate theoretical framework reflecting the interdisciplinary nature of entrepreneurship for developing a research design was crucial. An adapted entrepreneurshipin-network model was adopted based upon a synthesis derived from a study of three clusters of entrepreneurship models.

Cluster 1: The process models include the pursueopportunity models of Baron and Shane (2008), Van der Veen and Wakkee (2004) and Deakins and Whittam (2000); the life-cycle models of Granlund and Taipaleenmäki (2005), Kuratko and Hodgetts (1992), Robbins (1994), Victor and Boynton (1998), Miller and Friensen (1984) and Quinn and Cameron (1983); the entrepreneurs events model of Bygrave (1989); and the resource-based cumulative model of Haber and Reichel (2007). These models emphasised key activities that need to be performed in the pursuit of new user value by an entrepreneur in discrete, defined phases of a business. However, the models ignore the dynamic nature of a changing environment - challenges and tasks that may unfold in multiple ways. The models are also not able to accommodate periods of non-growth or reversal of growth as an option for survival.

Cluster 2: The interaction or relationship models include the structural network models of Groen (2005), Van der Veen and Wakkee (2004), Håkansson and Snehota (1995) and Håkansson (1989); the social identity models of Highhouse,
Thornbury and Little (2007), Korte (2007), Van Knippenberg and Hogg (2003) and Tajfel (1974); the social systems models described by Bjerke (2007), Parsons (1951) and Parsons and Shils (2001); and the regulatory focus model described by Brockner, Higgins and Low (2004). Interaction or relationship models recognise that interbusiness relationships are intrinsic to business success. A relationship is considered to be a 'mutually oriented interaction between two reciprocally committed parties implying mutual orientation and commitment over time' (Håkansson \& Snehota 1995:25). These relationships and their effect on other important business constructs such as business opportunity recognition, opportunity preparation, opportunity exploitation and the utilisation of the various types of capital, are important.

Cluster 3: The economic models include the transactional cost models described by Hogg (2007), Michael (2007) and Coase (1937); and the heterodox emerging model described by Minniti and Lévesque (2008). These models evaluate the economic performance of a business within a macroeconomic environment and within bounded rationality.

The adapted entrepreneurship-in-network framework adopted in this research (Figure 1) gives an indication of its stochastic nature as all components (actions to be conducted, resources, the behaviour of the actors, the interactions between the actors and the situation) are dynamic, heuristic and biased. Everything that occurs within the model is based on bounded rationality - a decision-making mode that varies between rule-following behaviour and purpose-seeking behavior - and fixed within a timeframe. It accommodates reverse processes that may influence the outcome of opportunity-seeking behaviour. The adapted model is highly complex as it displays a probability nature and not a deterministic nature. Furthermore, a possibility of greater variation and multidirectional development, as well as adaptation paths, can be followed. The possibility of multidirectional paths is supported by Achtenhagen, Naldi and Melin (2010) who stated that, unlike the suggestion of many models of organisational growth, even growing firms do not display unidirectional development paths.

Implicit in this model is that entrepreneurship is by its nature a social act within a specific type of social structure which creates value for the marketplace. As such entrepreneurship is, on the one hand, an order-creating act (creating a new equilibrium) and, on the other hand, an act that results in the creation of new contingencies. Whilst the entrepreneur remains the main driver of the entrepreneurial process, careful consideration of the influence of interacting actors and institutions influences the entrepreneur in his decision on what the business ought to be (identity) or ought to do (acceptable value to produce). In this regard, Hoang and Antoncic (2003) identify three critical elements, namely: the nature of the content that is exchanged between actors; governance mechanisms in relationships; and the network structure created by the cross-cutting relationships between actors in order to explain entrepreneurial outcomes. 
In the entrepreneurship-in-network approach as put forward by Van der Sijde (2007), interaction of actors takes place with regard to opportunity recognition, opportunity preparation and opportunity exploitation, all of which subsequently lead to value creation. This model does not represent a linear process, because changing circumstances may require the entrepreneur to re-evaluate decisions made in earlier stages. Mechanisms contained in the definitions by Parsons and Shils (2001) and Fry, Stoner and Hattwick (1998) showed that interaction between actors striving for goal attainment, optimisation of processes, maintenance of patterns and institutionalisation of shared symbols all produce their own specific types of capital, which are needed in the business. Each of these mechanisms is related to specific types of capital: interaction between actors is linked to a social capital; goal attainment is linked to strategic capital; optimisation of processes is linked to economic capital; and maintenance of patterns and institutionalisation of shared symbols is linked to cultural capital.

An assumption is made that a business needs sufficient capital in order to be sustainable over time; and that a business has to be in possession of sufficient capital in all four areas (social, strategic, economic and cultural) in order to be viable and successful. Furthermore, for a business to be sustainable and to grow, an entrepreneur has a continual need to achieve value creation. This is the reason for adding a value-creation-over-time dimension to the entrepreneurshipin-network model.

\section{Research method and design}

Watkins (2006) stated that a research problem should be formulated within the context of a particular research environment which then becomes the primary focus of the study. After careful evaluation of other dental laboratories in the Tshwane Metropolitan area, a laboratory was selected as being the most suitable business to justify the research project using a criterion-based benchmark approach based upon: the state-of-the-art technology employed; the spectrum of dental speciality services provided; the four critical types of capital

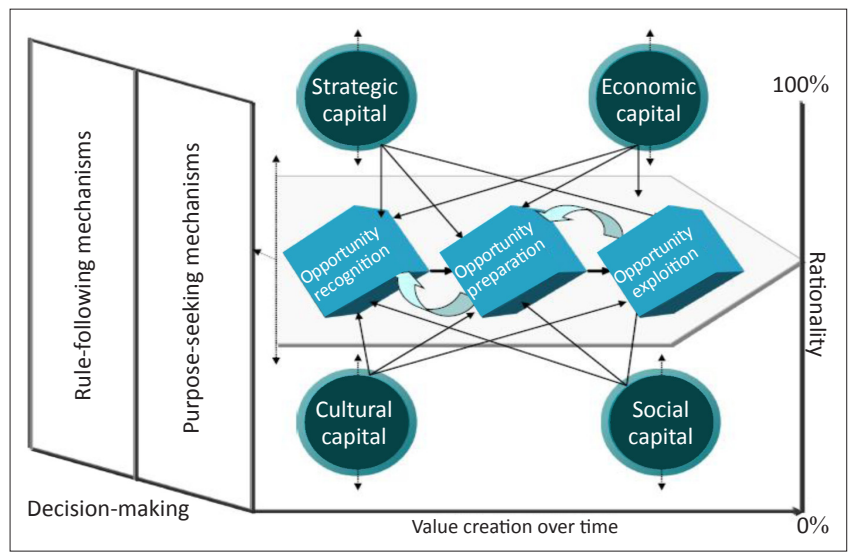

Source: Ferreira, C.M., 2011, 'Entrepreneurship-in-network adaptation and fixation of Pretoria dental laboratory', unpublished Master's dissertation, Faculty of Management Sciences, Business School, Tshwane University of Technology

FIGURE 1: Adapted entrepreneurship-in-network model. relevant to the study; and the lifespan of the business that allows for longitudinal data collection. The research design was based upon a cohort-survey research design aimed at generating longitudinal data covering the 16-year lifespan of the laboratory.

\section{Procedure}

The 16-year period was divided into three distinct periods. Each phase defined a priori market events representing transitional time periods in the life of the dental laboratory. The drivers causing transitions include examples such as business acquisitions and radical changes in the medical business environment. This resulted in the laboratory either adapting or fixating its entrepreneurship practices, values or styles, in either a reactive or proactive manner, to changes that have already occurred or were expected to occur. The generation of longitudinal data was considered to be important as it enabled the researchers to identify variables in the entrepreneurship-in-network approach that introduced fixation (stability) or adaptation into the entrepreneurial processes of the dental laboratory. Alasuutari, Bickman and Brannen (2008:230) define a cohort as an aggregate of individuals who experience the same events at the same time intervals. The researchers drew on the memory of research respondents to obtain longitudinal data on the single dental laboratory business research subject. For this reason, a fixed panel of respondents was selected, with no additions to or emigration from the sample permitted. The cohort remained stable during the execution of the research. To eliminate historical effects as a result of differences in the respondents' experiences and memories, the researchers opted for a standardised measuring instrument in order to minimise memory variance. This is in accordance with a recommendation made by Creasey (2006) regarding how to minimise historical effects. An interrupted time-series approach was followed in which responses from the same employee, supplier and customer were measured.

\section{Sampling protocol}

The study population of 125 people comprised one business owner, one financial auditor, 18 staff members, 88 customers and 17 suppliers. This population met the criteria decided upon, namely, that the sample could only be selected from a population in which: (1) respondents should have had a working business relationship with the business owner for at least one year; and (2) in the case of customers, only customers that have contributed more than $2 \%$ to the total revenue of the dental laboratory and, grouped together with others, contributed more than $60 \%$ to the total revenue, would be included in the research. The $2 \%$ criterion was decided upon because the customer base was relatively broad and the contributing size of customers was of approximately the same order. In the case of suppliers, this sample was loaded by a factor of 88:17 in order to ensure greater equality and balance in the perceptions of both the customers and suppliers.

To ensure sample representativity, validity and reliability, conditions were set for stratified sample selection, including the following: 
1. the business owner and the financial auditor would be included in the sample because of their respective positions

2. opinion equality should be ensured for both the suppliers and the customers of the dental laboratory, thus the researchers selected customer and supplier respondents on a proportionate basis calculated according to:

2.1. their monetary contribution to the financial performance of the dental laboratory

2.2. a prescribed minimum time period relationship with the laboratory

2.3. a declining sequence of business activity with the laboratory.

3. only those with an employment history of longer than a year at the dental laboratory were included in the study, as well as those employees indicated by the business owner as having had a close relationship with the laboratory. This was done in order to obtain reliable and valid information from employees.

Financial institutions were excluded from the sample as the researchers were of the opinion that the financial health of the dental laboratory could realistically be assessed by the financial auditor, who has had a 16-year relationship with the business.

The final sample size of 42 respondents comprised the business owner (to provide the researchers with a firsthand description of how entrepreneurial processes, critical types of capital and environmental adaptation occurred over a period of 16 years); the financial auditor of the dental laboratory (to provide objective information on the financial position, history and financial capitalisation); 12 staff members (to respond to questionnaires on cultural and social capital utilisation); and 16 customer respondents and 14 supplier respondents (to determine the trustworthiness, reliability, reputation and general entrepreneurial behaviour of the dental laboratory that have spelt success in a highly competitive dental laboratory marketplace). In order to ensure that no statistical power loss would occur, Hansen and Collins (1994:142) suggested that researchers should try to maintain the effective initial sample size. In this research, the cohort sample size remained the same.

\section{Data compilation and measuring instruments}

A triangulation data compilation approach was used, necessitated by the small sample size available, including interviews, structured questionnaires and financial reports. The content of each was informed by the adopted theoretical framework and the purpose of the research, namely, to focus on the adaptation and fixation entrepreneurial approaches in the dental laboratory over its lifespan. The adaptation and fixation concepts were evaluated in terms of stability (fixation) and changes (adaptation) in four critical capitals, which were defined as:

- cultural capital, representing the complex set of ideologies, symbols and core values applicable throughout the laboratory that influenced the way in which business is conducted
- economic capital, representing the allocation of economic resources for productive purposes and the state of health of the financial capital in the laboratory

- social capital, representing a community of people in which diverse members of the laboratory are bonded through ties and the ability of actors to interact with other actors

- strategic capital, representing the growth intent and the risk-orientation preference of the entrepreneur of the laboratory and the leveraging of internal resources, capabilities and core competencies to accomplish the growth intent and risk profile in the health environment.

The variables were measured at an ex post facto level, as longitudinal data were gathered in retrospective. The main aims of the open-ended interview with the business owner were, firstly, to explore how the entrepreneurship-in-network approach was used by the dental laboratory in the business adaptation and fixation process, secondly, to identify the critical factors or incidents that introduced a transitional period in its lifespan and thirdly, to identify the adaptation and fixation that had occurred during capital formation. The structured self-administered questionnaire to staff members probed changes and stability in the formation of the social and cultural capital of the DL. The self-administered questionnaires to the customers and suppliers probed adaptation and fixation in social capital formation as they relate to bonding ties with the specific intent of evaluating the trustworthiness and reputation of the dental laboratory. Stability and changes in economic capital were based upon audit reports by the financial auditor compiled according to investments, allocation of funds or economic resources and the state of health of the financial capital of the laboratory.

\section{Analysis}

The qualitative data obtained from the open-ended interview were analysed using a two-layer process. The firstlayer analysis was to determine the common factors resulting in adaptation or fixation, using a post-coding consensusseeking approach between the two researchers and the business owner, whilst the second layer of cause-effect analysis was done according to Mill's method of analysis, following the first two steps of the prescribed five-step procedure of establishing cause and effect by means of the methods of agreement and difference (Lau \& Chan 2008). Interview biases were controlled by explaining the purpose of the research and the interview, explaining the interview structure that would be followed, reading the principal questions as worded in the interview protocol, providing neutral explanations when requested to do so and probing secondary questions in a non-directive manner. Financial capital was analysed according to basic accounting metrics. These analyses were considered sufficient to determine how the dental laboratory adapted over time in response to changing circumstances in the dental environment.

\section{Results}

The qualitative data revealed that gaps in the critical factors described by Table 1 were responsible for transitions that 
TABLE 1: Critical factors causing transition.

\begin{tabular}{|c|c|c|c|}
\hline Transitional Period & Critical Factors & Description status & Adaptation/Fixation \\
\hline \multirow[t]{3}{*}{$\begin{array}{l}\text { Period } 1 \\
\text { 1992-1996 }\end{array}$} & 1. Social capital & $\begin{array}{l}\text { Lack of trust, non-fulfilment of needs, poor management of } \\
\text { the laboratory and few cooperative interactions with staff, } \\
\text { customers and suppliers. }\end{array}$ & \multirow{3}{*}{$\begin{array}{l}\text { Forced buy-out of dental laboratory at low cost; change in } \\
\text { the vision of the dental laboratory occurred; and change } \\
\text { in the value system of the dental laboratory introduced; } \\
\text { greater variety of services. }\end{array}$} \\
\hline & 2. Strategic capital & $\begin{array}{l}\text { A need to leverage resources and capabilities; overcome lack } \\
\text { of entrepreneurship growth; and promote business growth. }\end{array}$ & \\
\hline & 3. Economic capital & $\begin{array}{l}\text { Inability to utilise funds for productive purposes; poor } \\
\text { financial health of laboratory; and absence of economic } \\
\text { objectives, profits and savings. }\end{array}$ & \\
\hline \multirow{2}{*}{$\begin{array}{l}\text { Period } 2 \\
1997-2001\end{array}$} & & $\begin{array}{l}\text { Provide quality service and punctual delivery of service to } \\
\text { customers. }\end{array}$ & $\begin{array}{l}\text { Instill value system of time management, product } \\
\text { aesthetics and on time production outputs; create flexible } \\
\text { business structure; build social and human capital. }\end{array}$ \\
\hline & & Rationality. & $\begin{array}{l}\text { Balance income and expenditure; cash-on-delivery } \\
\text { business; maintain close relationships with customers and } \\
\text { suppliers; create an accessible and approachable business; } \\
\text { follow ethical code of Dental Health industry. }\end{array}$ \\
\hline
\end{tabular}

occurred in each of the three distinct periods of the dental laboratory and which resulted in appropriate adaptation and fixation responses.

The findings are presented in terms of the entrepreneurial adaptation and fixation processes as they occurred during the three transition periods in the lifespan of the dental laboratory. Table 1 reveals that the first adaptation driver in the early lifespan of the laboratory was initiated by the fact that the social capital factor hindered the achievement of productive outcomes and the accomplishment of goals because of a lack of trust, non-fulfilment of needs, poor management of the laboratory and few cooperative interactions with staff, customers and suppliers. The second most important driver for adaptation in the early lifespan of the laboratory was the strategic capital component. A need existed to leverage resources and capabilities better in order to overcome the lack of entrepreneurship growth in the laboratory and to promote business growth. The third most important driver for change was the economic capital component. During the early phases, an inability to utilise funds for productive purposes existed and the business found itself in a poor financial situation in the absence of economic objectives, profits and savings, limited economic resources and the relatively low market value of the laboratory. Adaptation occurred, causing improved overall business growth results because of a change in the vision, an improvement of the administrative systems in the laboratory, the taking of personal responsibility for the direction in which the dental laboratory was moving by the business owner and a desire instilled in all employees to establish a bigger laboratory that offered a greater variety of services. The fourth adaptation was caused by a change in cultural capital when a new set of cultural values was introduced into the laboratory, namely, to be consistent at all times, to be loyal to the dental laboratory and to provide excellent customer service. The cultural capital became fixed over the whole lifespan of the laboratory and has become a 'living culture', as it still forms the foundation on which the business builds its success.
In phases 2 and 3 of the lifespan, it was exactly the same capital that enhanced the productive outcomes of the dental laboratory, but was now caused by factors relating to deep respect for the dignity of others, trust in each other, feeling free to interact with other actors and being kept informed. A hindering factor in the adaptation process that remained a stumbling block was the perceived inability of all the respondents to influence any decision making in the business. With a greater focus on the more productive utilisation of funds, the investment profile of the laboratory has increased to such an extent that it could better manage business risks, pay current invoices, fulfil its short-term commitments and become less dependent on overdraft facilities. The returns on equity improved during all life stages of the dental laboratory, indicating a constant improvement in its financial efficiency. As time passed, the business owner instilled a value system that became ingrained. The strategic plan of the dental laboratory was changed and has, over the last time phases, become fixated on creating a business that possesses the following characteristics: (1) cash-on-delivery business; (2) great adaptability and flexibility in response to customer demands; (3) an accessible and approachable demeanour, both to the customer and its supplier base; (4) a high regard for its customers, suppliers and employees; (5) management according to a value system and not according to internal policies and regulations; and (6) a management philosophy of achieving business stability first, followed by business growth.

Table $2 \mathrm{a}$ and $2 \mathrm{~b}$ reveals the substantial economic capital im-provements that occurred in the dental laboratory based upon the statistical tests and the accounting information.

\section{Discussion}

\section{Implications of the research}

The results provided evidence consistent with that of Sun (2008) and Zhong (2009), in that when the cultural values in a business becomes fixated, as in this research, then they act as the 'parent'-actor in the business's constitution and all of its 
TABLE 2a: Critical capital improvements over lifespan.

\begin{tabular}{|c|c|c|c|c|}
\hline \multirow{2}{*}{$\begin{array}{l}\text { Economic performance } \\
\text { (Economic capital) }\end{array}$} & \multirow[t]{2}{*}{ Indicators } & \multicolumn{3}{|c|}{ Improvement in three transition periods } \\
\hline & & Period 1 (1992-1996) & Period 2 (1997-2001) & Period 3 (2002-2007) \\
\hline \multirow[t]{5}{*}{ Investment profile index } & Cash in hand & 1.00 & 0.00 & 2.39 \\
\hline & Overdraft & 1.00 & 0.54 & 0.14 \\
\hline & Loans & 1.00 & 3.27 & 3.78 \\
\hline & Debtors & 1.00 & 1.26 & 2.06 \\
\hline & Investment capital & 1.00 & 1.13 & 3.84 \\
\hline \multirow[t]{3}{*}{ Return on investment } & Profit before tax & Unknown & $59.20 \%$ & $87.72 \%$ \\
\hline & Nett asset turnover & Unknown & $300.97 \%$ & $300.98 \%$ \\
\hline & Fixed asset turnover & Unknown & $3233.31 \%$ & $4400.64 \%$ \\
\hline \multirow[t]{4}{*}{ Performance } & Turnover & 1.00 & 1.07 & 3.48 \\
\hline & Gross profit & 1.00 & 1.48 & 4.52 \\
\hline & Nett profit & 1.00 & 1.45 & 7.28 \\
\hline & Profit margin & 1.00 & $11.02 \%$ & $30.32 \%$ \\
\hline
\end{tabular}

TABLE 2b: Critical capital improvements over lifespan.

\begin{tabular}{|c|c|}
\hline Critical capital & Improvement in three transition periods \\
\hline Social capital & $\begin{array}{l}\text { Trustworthiness: Laboratory is considered to be honest, behaves in consistent manner, acts with integrity, is responsible and reliable business. } \\
\text { Reputation: Laboratory has a good name in the dental environment, maintains quality relationships with customers and suppliers and it is one of the } \\
\text { best laboratories in the business. }\end{array}$ \\
\hline Strategic capital & Better resource balancing occurred to position the laboratory for growth and expansion. \\
\hline Cultural capital & No substantial changes in the cultural capital that represents core values and ideology occurred. Cultural capital remained fixated. \\
\hline
\end{tabular}

practices, as cultural capital gives guidance to staff members on what is right, as well as what is complementary to and of mutual benefit to both the dental laboratory and its clients. Adaptation in terms of responding to business and dental environmental changes occurred in all the other critical capitals, showing the importance of having sufficient capital and of integrating the critical types of capital or resources in such a way that a growing and sustainable business can be created with good prospects for the future.

\section{Conclusion}

This study represents a first business case on adaptation and fixation using the entrepreneurship-in-network approach to evaluate the development progress of a dental laboratory and can thus be considered to be base-line research that could introduce comparative studies in this field. The principal contribution of the study is that an adapted entrepreneurship-in-network theoretical framework was introduced which could be used for future research and to validate the research findings achieved. This case demonstrated that the principles by which the entrepreneur gives strategic direction would became ingrained values by which the business is defined and respected. It also demonstrated that both a lack of and a sufficient amount of a particular capital may drive the adaptation process in a business, either for better or for worse.

\section{Acknowledgements Competing interests}

The authors declare that they have no financial or personal relationship(s) which may have inappropriately influenced them in writing this article.

\section{Authors' contributions}

C.M.F. (Tshwane University of Technology) acted as project leader, whilst J.P.G. (Tshwane University of Technology) was responsible for the research design and analysis. Both researchers were responsible for data compilation and interpretation.

\section{References}

Achtenhagen, L., Naldi, L. \& Melin, L., 2010, “"Business growth”: Do practitioners and scholars really talk about the same thing?'. Entrepreneurship Theory and Practice 34(2), 289-316. http://dx.doi.org/10.1111/j.1540-6520.2010.00376.x

Alasuutari, P., Bickman, L. \& Brannen, J., 2008, The SAGE handbook of social research methods, SAGE Publications Ltd, London.

Baron, R.A. \& Shane, S.A., 2008, Entrepreneurship: a process perspective, 2nd edn., Thomson South-Western, Mason, $\mathrm{OH}$.

Bjerke, B., 2007, Understanding entrepreneurship, Edward Elgar Publishing Inc. Northampton.

Brockner, J., Higgins, E.T. \& Low, M.B., 2004, 'Regulatory focus theory and the entrepreneurial process', Journal of Business Venturing 19(2), 203-220. http:// dx.doi.org/10.1016/S0883-9026(03)00007-7

Bygrave, W.D. 1989, 'The entrepreneur paradigm (I): A philosophical look at its research methodologies', Entrepreneurship Theory and Practice 14(1), 7-26.

Coase, R.H., 1937, 'The nature of the firm', Economia 4(16), 386-405.

Coulter, M., 2001, Entrepreneurship in action, Prentice Hall, Upper Saddle River, NJ.

Creasey, G.L., 2006, Research methods in lifespan development, Pearson, Boston, MA.

Deakins, D. \& Whittam, G., 2000, 'Business start-up: Theory, practice and policy', in S. Carter \& D. Jones-Evans (eds.), Enterprise and small business: principles, practice and policy, pp. 115-131, Financial Times Prentice-Hall, London.

Ferreira, C.M., 2011, 'Entrepreneurship-in-network adaptation and fixation of Pretoria dental laboratory', unpublished Master's dissertation, Faculty of Management Sciences, Business School, Tshwane University of Technology, Pretoria.

Fry, F.L., Stoner, C.R. \& Hattwick, R.E., 1998, Business: An integrative framework, Irwin McGraw-Hill, Boston, MA.

Granlund, M. \& Taipaleenmäki, J., 2005, 'Management control and controllership in new economy firms - a life cycle perspective', Management Accounting Research 16(1), 21-57. http://dx.doi.org/10.1016/j.mar.2004.09.003

Groen, A.J., 2005, 'Knowledge intensive entrepreneurship in networks: Towards a multi-level/multi dimensional approach', Journal of Enterprising Culture 13(1), 69-88. http://dx.doi.org/10.1142/S0218495805000069

Håkansson, H., 1989, Corporate technological behaviour: Co-operation and networks, Routledge, London.

Håkansson, H. \& Snehota, I., 1995, Developing relationships in business networks, Routledge, London.

Hansen, W.B. \& Collins, L.M., 1994, 'Seven ways to increase power without increasing $\mathrm{N}$ ', in L.M. Collins \& L. Seitz (eds.), Advances in data analysis for prevention research, National Institutes of Health: National Institute on Drug Abuse Research Monograph 142

Haber, S. \& Reichel, A., 2007, 'The cumulative nature of the entrepreneurial process: The contribution of human capital, planning and environment resources to small venture performance', Journal of Business Venturing 22(1), 119-145. http:// dx.doi.org/10.1016/j.jbusvent.2005.09.005 
Highhouse, S., Thornbury, E.E. \& Little, I.S., 2007, 'Social-identity functions of attraction to organizations', Organizational Behaviour and Human Decision attraction to organizations', Organizational Behaviour and Human Decision
Processes 103(1), 134-146. http://dx.doi.org/10.1016/j.obhdp.2006.01.001

Hoang, H. \& Antoncic, B., 2003, 'Network-based research in entrepreneurship: A critical review', Journal of Business Venturing 18(2), 165-187. http://dx.doi. org/10.1016/S0883-9026(02)00081-2

Hogg, M.A., 2007, 'Uncertainty-identity theory', Advances in Experimental Social Psychology 39, 69-126. http://dx.doi.org/10.1016/S0065-2601(06)39002-8

Korte, R.F., 2007, 'A review of social identity theory with implications for training and development', Journal of European Industrial Training 31(3), 166-180. http:// dx.doi.org/10.1108/03090590710739250

Kuratko, D.F. \& Hodgetts, R.M., 1992, Entrepreneurship: A contemporary approach, 2nd edn., The Dryden Press, Orlando.

Lau, J. \& Chan, J., 2008, Mills's methods [Tutorial S05], viewed 26 August 2008, from http://philosophy.hku.hk/think/sci/mill.php

Michael, S.C., 2007, 'Transaction cost entrepreneurship', Journal of Business Venturing 22(1), 119-145.

Miller, D. \& Friesen, P.H., 1984, 'A longitudinal study of the corporate life cycle' Management Science 30(10), 1161-1183. http://dx.doi.org/10.1287/ mnsc.30.10.1161

Minniti, M. \& Lévesque, M., 2008, 'Recent developments in the economics of entrepreneurship', Journal of Business Venturing 23(6), 603-612. http://dx.doi. org/10.1016/j.jbusvent.2008.01.001

Parsons, T., 1951, The social system, The Free Press, New York.

Parsons, T. \& Shils, E.A., 2001, Toward a general theory of action: theoretical foundations for the social sciences, Harvard University Press, Cambridge, MA.
Quinn, R.E. \& Cameron, K., 1983, 'Organizational life cycles and shifting criteria of effectiveness: Some preliminary evidence', Management Science 29(1), 33-51. $\mathrm{http}: / / d x . d o i . o r g / 10.1287 / \mathrm{mnsc} 29.1 .33$

Robbins, S.P., 1994, Management, 4th edn., Prentice-Hall, Inc., New Jersey.

Sun, S., 2008, 'Organizational culture and its themes', International Journal of Business and Management 3(12), 137-141.

Tajfel, H., 1974, 'Social identity and intergroup behaviour', Social Science Information 13(2), 65-93. http://dx.doi.org/10.1177/053901847401300204

Timmons, J.A., 1999, New venture creation: Entrepreneurship for the 21st century, 5th edn., Irwin/McGraw-Hill, Boston, MA.

Van Der Sijde, P.C., 2007, 'Value creation', unpublished article, The Dutch Institute for Knowledge Intensive Entrepreneurship (NIKOS), University of Twente, Twente.

Van der Veen, M. \& Wakkee, I.A.M., 2004, 'Understanding entrepreneurship', in D.S Watkins (ed.), Annual review of progress in entrepreneurship research, Vol. 2 2002-2003, pp. 114-152, European Foundation for Management Development, Brussels.

Van Knippenberg, D. \& Hogg, M.A., 2003, 'A social identity model of leadership effectiveness in organizations', Research in Organizational Behavior 25, 243-295. http://dx.doi.org/10.1016/S0191-3085(03)25006-1

Victor, B. \& Boynton, A.C., 1998, Invented here: Maximizing your organization's internal growth and profitability, Harvard Business Review Press, Boston, MA

Watkins, J.A., 2006, Theses/dissertations/research reports: A practical guide for students to the preparation of written presentations of academic research, Post-graduate office, Tshwane University of Technology, Pretoria.

Zhong, P., 2009, The effect of Chinese business culture on joint venture success, Master's dissertation, Department of Management and Entrepreneurship, Faculty of Management Sciences, Tshwane University of Technology, Pretoria.

Zimmerer, T.W. \& Scarborough, N.M., 2002, Essentials of entrepreneurship and small business management, 2nd edn., Prentice Hall, New York, NY. 